\title{
Extreme selection in humans against homeotic transformations of cervical vertebrae
}

Frietson Galis (f.galis@biology.leidenuniv.nl)

Tom J.M. Van Dooren (vdooren@rulsfb.leidenuniv.nl)

Johan D. Feuth (j.feuth@12move.nl)

Johan A.J. Metz (j.a.j.metz@biology.leidenuniv.nl)

Andea Witkam (witkam@rulsfb.leidenuniv.nl)

Sebastiaan Ruinard (atsruinard@hotmail.com)

Marc J. Steigenga (marcsteig@gmail.com)

Liliane C.D. Wijnaendts (Icd.wijnaendts@vumc.nl)

\section{Approved by}

Ulf Dieckmann

Program Leader, Evolution and Ecology Program

December 2006 


\section{Contents}

Abstract... 


\section{EXTREME SELECTION IN HUMANS AGAINST HOMEOTIC \\ TRANSFORMATIONS OF CERVICAL VERTEBRAE}

Frietson Galis ${ }^{1}$, Tom J. M. Van Dooren ${ }^{1}$, Johan D. Feuth ${ }^{2}$, Johan A. J. Metz ${ }^{1,3}$, Andrea

Witkam, Sebastiaan Ruinard ${ }^{1}$, Marc J. Steigenga ${ }^{1,5}$, Liliane C. D. Wijnaendts ${ }^{4}$

1. Institute of Biology, Leiden University, P.O. Box 9516, 2300 RA Leiden, The Netherlands

2. Department of Surgery, Leiden University Medical Centre, Leiden, The Netherlands

3. International Institute for Applied Systems Analysis, Evolution and Ecology Program

\section{A-2361 Laxenburg, Austria}

4. Department of Pathology, Free University Medical Centre (VUMC), 1081 BT,

Amsterdam, The Netherlands

5. Present address: Department of animal ecology I, University of Bayreuth, D-95440, Bayreuth, Germany

Main Text: 5125 words, abstract 161 words, 3 figures, 4 tables.

LRH: F. Galis et al.

RRH: Extreme selection against homeotic changes

Key words: Body plans, Hox genes, pleiotropy, developmental constraint, modularity, phylotypic stage, evolutionary medicine 


\begin{abstract}
Why do all mammals, except for sloths and manatees, have exactly seven cervical vertebrae? In other vertebrates and other regions, the vertebral number varies considerably. We have investigated whether natural selection constrains the number of cervical vertebrae in humans. To this end, we have determined the incidence of cervical ribs and other homeotic vertebral changes in radiographs of deceased human fetuses and infants, and analysed several existing datasets on the incidence in infants and adults. Our data show that homeotic transformations that change the number of cervical vertebrae are extremely common in humans, but are strongly selected against: almost all individuals die before reproduction. Selection is most probably indirect, caused by a strong coupling of such changes with major congenital abnormalities. Changes in the number of thoracic vertebrae appear to be subject to weaker selection, in good correspondence with the weaker evolutionary constraint on these numbers. Our analysis highlights the role of prenatal selection in the conservation of our common body plan.
\end{abstract}


The exceedingly low level of interspecific variation in the number of cervical vertebrae of mammals has puzzled biologists for more than 150 years (E.g. Cuvier 1835; Flower and Lydekker 1891). In birds, reptiles and amphibians, this number varies considerably, and in mammals the number of vertebrae in other vertebral regions is variable as well (Fishel 1906; Galis 1999; Narita and Kuratani 2005). Thus, there appears to be an evolutionary constraint on variations in the mammalian cervical region. Earlier we have suggested that this constraint is the result of selection against deleterious pleiotropic effects associated with variations in the number of cervical vertebrae (Galis 1999). According to this hypothesis selection is, thus, indirect: variations of the number of cervical vertebrae are not disadvantageous as such, but they are associated with other disadvantageous changes. Support for the hypothesis comes from the observation that changes in the number of cervical vertebrae appear to be associated with an increased susceptibility to pediatric cancers, congenital abnormalities and still births in humans and mice (Gladstone and Wakeley 1932; Adson and Coffey 1947; Schumacher et al. 1992; Keeling and Kjaer 1999; Galis and Metz 2003; Merks et al. 2005; Steigenga et al. 2006). In addition, the number of cervical vertebrae is determined during the early organogenesis stage and the conservation of this stage is thought to be the result of selection against deleterious pleiotropic effects of mutations that have an effect on this stage (Sander 1983; Raff 1994; Galis and Metz 2001).

To test this hypothesis, one needs a quantitative study in which the strength of selection against changes of the number of cervical vertebrae is measured and compared with the strength of selection against a less effectively constrained evolutionary change, e.g. changes of the number of thoracic vertebrae. In addition, one needs to establish whether the observed selective disadvantage is indeed the result of deleterious pleiotropic effects that are associated with changes in the number of cervical vertebrae. 
To measure the strength of the selection against variations in the number of cervical and thoracic vertebrae we have analysed in humans to which extent variations in the number of cervical and thoracic vertebrae are more prevalent in deceased fetuses and infants than in individuals that survive to a reproductive age. We have screened 598 fetuses and infants that died between 1992 and 1999 in the VU Medical Center in Amsterdam for variations in cervical and thoracic vertebral number and compared the results with existing data on prevalence of vertebral variations in the population at large. Furthermore, to investigate whether selection against vertebral variations is due to pleiotropic effects, we have tested for significant associations between variations in vertebral numbers and congenital abnormalities with deleterious effects.

\section{MATERIAL AND METHODS}

\section{Radiographs}

Since 1980 all fetuses and infants that are presented for autopsy at the VU Medical Centre in Amsterdam have been standardly radiographed $(23 \mathrm{~mA}, 70-90 \mathrm{kV}, 4-12 \mathrm{sec}$, Agfa Gevaert D7DW Structurix films, Figure 1) both ventrally and laterally. We analysed all radiographs made from 1992-1999 (598 cases). In the analysis, we only included fetuses older than 14 weeks, since this is the earliest stage at which ossification centres of cervical ribs can reliably be detected in radiographs (Noback and Robertsen 1951; McNally et al. 1990). ). In total, 30 fetuses were excluded from analysis because of insufficient ossification. Fetuses from abortions induced for medical reasons (fatal abnormalities) have been included, except for the calculation of the effect of age at death. Furthermore, infants were analysed that died before the age of one year. At least two people independently analysed each radiograph for variations of vertebral numbers, without prior knowledge of the autopsy reports (however, several congenital anomalies 
can be seen in radiographs). Radiographs that were difficult to interpret, or where the interpretation differed between observers, were excluded (44 cases for cervical ribs). Difficulties in interpretation of vertebral variations were due to either insufficient contrast, or because the scapula, maxilla or teeth were obstructing the view of potential cervical ribs. When a cervical rib could only be documented on one side, radiographs were excluded for the scoring of bilateral symmetry (20 cases) and radiographs with an obstructed view of the $19^{\text {th }}$ vertebrae were excluded for the scoring of absent or rudimentary twelfth ribs (4 cases). Absent or rudimentary ribs on the 19 th vertebra were scored as absent or rudimentary $12^{\text {th }}$ ribs, except when a cervical rib was also present (since somites from which the vertebrae develop arise and are being patterned in rostrocaudal order). Rudimentary ribs on the $20^{\text {th }}$ vertebra were scored as lumbar ribs except when a rudimentary first rib was also present. In two cases a cervical rib was present in combination with the absence of ribs on the $18^{\text {th }}$ vertebra; these cases were scored as a cervical rib and an absent $12^{\text {th }}$ rib. In two cases a cervical rib was present in combination with ribs on the $20^{\text {th }}$ vertebra; these cases were scored as a cervical rib and a lumbar rib.

\section{Diagnosis of abnormalities and diseases}

Standard autopsy reports were made by pathologists and filed in a national pathological archive (PALGA). We searched the reports for single and multiple congenital abnormalities and, if documented, cytogenetic abnormalities. Furthermore, we distinguished between minor and major congenital abnormalities following Merks et al.(2003) for external and skeletal abnormalities and Lancaster and Pedisich (1995) for further abnormalities. We opted for a classification in terms of minor/major and single/multiple abnormalities, because it reflects our expectations on the strength of the deleterious effects of these abnormalities. The condition of the environment (e.g. the mother) and the condition of the individual both influence the chance of a premature 
death. Hence, the strength of the deleterious effects of the abnormalities provides information on the selective disadvantage. Examples of minor congenital abnormalities are hypertrophy of the heart, spleen, liver or lungs, supernumerary phalanges, club foot, hydrops foetalis (edema of the whole body), ventricular septal defect (defect in the wall that separates the left and right ventriculi of the heart), atrial septum defect (defect in the wall that separates the left and right atria of the heart), patent foramen ovale (persistence of the fetal opening between left and right atria), patent truncus arteriosus (persistence of the fetal structure between the left pulmonary artery and the descending aorta), omphalocele (intestines and other abdominal organs protrude into the base of the umbilical cord) and slight facial dysmorphologies. Examples of major congenital abnormalities are the absence of one or both kidneys, anencephaly and other failures of neural tube closure (Figure 2), absence of the corpus callosum in the brain, cyclops, cleft lip/palate, tracheo-esophageal fistula (abnormal passage between trachea and oesophagus), atresia of the aorta, dextroposition of the heart, monoventricular heart, mono-atrial heart, various chondrodysplasias (abnormally short and deformed limbs) and sirenomelia (abnormal development of the caudal part of the body with different degrees of fusion of the legs). In addition we considered dysmaturity and embryonal tumours to be major abnormalities and prematurity a minor abnormality.

\section{Statistical analysis}

We used generalized linear modelling techniques for analysis (Agresti 2002). Probabilities of occurrence of vertebral variations were studied by means of logistic regression, associations were investigated using log-linear analysis. In the log-linear analyses all associations between explanatory variables (types of congenital anomalies) were fitted in the models, in addition to associations of vertebral variations with congenital anomalies. This approach was followed because an analysis based on marginal totals of the contingency table alone can easily lead to incorrect conclusions 
about an association, i.e., an association between vertebral variations and one classification variable of congenital abnormalities can reverse sign when the occurrences in different groups (categories of other classification variables of congenital anomalies) are pooled (Simpson's paradox, Simpson 1951). In all cases, we checked for overdispersion of the data relative to the model. We used backward model selection (from elaborate to simpler) to compare models and test hypotheses. Model comparison was done using likelihood ratio tests for nested models, and AIC (Akaike Information criterion, Akaike 1973) for non-nested models. Only test statistics from the selected logistic regression models and log-linear models are presented. Throughout a significance level of $95 \%$ was used. Confidence intervals reported for probabilities of occurrence are calculated from logistic regression models (Venables and Ripley 2002).

\section{Incidence of vertebral variations in the general adult population}

In order to estimate the prevalence of cervical, rudimentary first, absent or rudimentary twelfth or lumbar ribs in the general adult population, we analyzed a number of existing datasets, chosen such that datasets of diseased populations were excluded (see Table 1). We fitted a binomial regression model for the incidence of each variation, with type of study (radiographic, dried skeletons) and study as factors. This model was simplified parameter-by-parameter until all remaining effects were significantly different from zero. In this manner we lumped studies where differences in incidence were nonsignificant, for instance because of relatively low sample sizes of vertebral variations. The estimates reported for the calculation of the selective disadvantage are the maximum among the predicted values from the selected model for cervical ribs and the minimum one for absent or rudimentary twelfth ribs.

\section{Selection against vertebral variations}

In order to arrive at estimates of selection pressures we calculated the survival pattern of individuals with or without a cervical rib and an absent or rudimentary $12^{\text {th }}$ rib, starting 
from clinically recognized pregnancies. Our calculations are based on an age-structured population model with four age classes (numbered zero to three) and calculations are presented in Tables 2 and 3. We have assumed for the general population in Western Europe that the probability of death is $\mu_{0}=0.15$ in the age interval before birth, $\mu_{1}=$ 0.01 of neonatal mortality from birth to one year of age, approximately zero mortality in the interval from age one to maturity, $\mu_{2}=0$ (Regan et al. 1989; De Galan-Roosen et al. 1998; Cartlidge and Stewart 1995; Eurocat Report 1997, 1999; Saraiya et al. 1999; Nolte et al. 2000; Van Duin 2002). Adults must die, $\mu_{3}=1$. The calculations proceed as follows. Survival up to age $S_{\mathrm{i}}$ in the general population is equal to $S_{\mathrm{i}}=\left(1-\mu_{\mathrm{i}-1}\right) \mathrm{S}_{\mathrm{i}-1}$, with $\mathrm{S}_{0}=1$. The prevalence of ribs among deaths that occurred in age class $i$ are denoted $p_{i}$. We obtained those prevalence parameters from our data analysis. The prevalence $P_{\mathrm{i}}$ among the group that is alive in age $i$ is equal to the prevalence among those that die from that class and those that survive into the next age, weighted by the probabilities of dying, resp surviving. This gives expression $P_{i}=\mu_{i} p_{i}+\left(1-\mu_{i}\right) P_{i+1}$. From this prevalence $P_{\mathrm{i}}$ and survival $S_{\mathrm{i}}$ one can calculate the survival probability of individuals with a rib up to age $i$ as $S_{R i}=P_{i} S_{i} / P_{0}$. The survival probability of individuals without a rib variation becomes $S_{N O R i}=\left(1-P_{i}\right) S_{i} /\left(1-P_{0}\right)$.

\section{RESULTS}

The incidence of cervical ribs (a rib on the seventh cervical vertebra, Fig.1) in deceased fetuses and infants was extremely high relative to the incidence in adults estimated from dry skeletons and radiographs (54.8 (confidence interval 50.5-59.0) \% versus 1.1 (0.32.0) $\%$ in the study on adults with the highest incidence, see Table 1). Using backward model selection in a logistic multiple regression, we found no significant effects of age 
at death, weight, year nor sex on the prevalence of cervical ribs. The absence of an age effect (slope 0.0001 (s.e. 0.0003 ); $\chi^{2}=0.18, \mathrm{p}=0.67$ ) is evidence that cervical ribs don't disappear later in development. We had no cases of completely absent first ribs. Rudimentary first ribs were rare $(2.1(1.1-3.6) \%$ versus $0.5(0.3-0.9) \%$ in the reference populations). The incidence of absent or rudimentary twelfth thoracic ribs is 5.6 (3.87.7) \% (versus $3.0(2.2-4.0) \%$ in the reference populations), of lumbar ribs $1.3(0.58-$ 2.6) \% (versus 8.8 (6.6-11.3) \% in the reference populations). These incidences showed no age-dependence either. Possibly, the incidence of lumbar ribs in deceased fetuses and infants is somewhat underestimated due to a delay in ossification of lumbar ribs compared to thoracic ribs. There was no significant difference between the incidences of fetuses from abortions for medical reasons and fetuses that died naturally $\left(\chi^{2}=0.001\right.$, $\mathrm{p}>0.9)$.

\section{Selection against cervical Ribs}

We calculated the average selective disadvantage, combining our results with those on frequencies of cervical ribs in adults and common survival patterns of human populations. Using the lower confidence limit for the selective difference (the minimal reasonable estimate of selective disadvantage), we found that at least $78 \%$ of the individuals in recognized pregnancies with a cervical rib die before birth and $83 \%$ before one year (Table 2). For individuals without cervical ribs $9 \%$ are dead by one year of age. The relative probability of survival of individuals with cervical ribs to one year of age, compared to individuals without, is at most $19 \%$. If we assume that all individuals for which radiographs were difficult to assess have no cervical ribs, then at least $76 \%$ of the individuals with a cervical rib would die before birth and $81 \%$ before one year. The relative probability of survival of individuals with cervical ribs to one 
year of age, compared to individuals without, would increase to $21 \%$. One can conclude that our conclusions are at most little biased by the missing observations.

\section{Weaker Selection against a Change at the thoraco-lumbar Boundary}

We repeated the above calculations for absent and rudimentary twelfth thoracic ribs, using the upper confidence limit for the selective difference (the maximal reasonable estimate of selective disadvantage). We found that at most $38 \%$ of the individuals of recognized pregnancies with an absent or rudimentary twelfth rib die before birth and $40 \%$ before age one (Table 3). Hence, the relative probability of survival of individuals with absent or rudimentary twelfth ribs compared to individuals without this variation is $73 \%$. Assuming that all four individuals for which radiographs were difficult to assess at the thoraco-lumbar boundary had absent or rudimentary 12 th thoracic ribs, this relative probability decreases to $70 \%$. Thus, this conservative calculation indicates that selection against a change at the thoraco-lumbar boundary is much weaker than that against a change at the cervico-thoracic one.

\section{Association of cervical ribs with congenital abnormalities}

The incidence of major anomalies in deceased fetuses and infants was 66.7 (62.4 - 70.9) $\%$. In $64.2(59.7-68.5) \%$ of the cases, multiple abnormalities were present. As a next step in our analysis, we investigated whether an association with congenital abnormalities could possibly explain the observed early deaths. The incidence of cervical ribs was indeed found to be positively associated either with multiple or with major congenital anomalies (both $\mathrm{P}\left[>\chi^{2}\right]=0.001$, see also the raw data in Table 4). A model including an effect of major anomalies fits the data better than one including 
multiple anomalies, based on the AIC (AIC major anomalies 611.1, AIC multiple anomalies 613.9) The highest incidence of cervical ribs (63.6\% (57.4-69.4\%), Fig.3) was found in fetuses and infants with both multiple and major abnormalities. This significant association between cervical ribs and the most deleterious class of abnormalities, and the parallel association between cervical ribs and the total number of mildly or strongly deleterious effects supports our hypothesis that the presence of cervical ribs is selectively disadvantageous because of associated negative pleiotropic effects.

Next to a positive association with major or multiple anomalies, no further significant, or higher-order, associations of variables with the incidence of cervical vertebrae were found. We found no effects of age or weight on the association and no association with sex. No other vertebral variations were significantly associated with any of the mentioned variables. It is of some interest to note that the few cases of rudimentary first ribs were always associated with major congenital abnormalities, even though the incidence was too low for reaching significance.

\section{Unilateral ribs}

In $22.8 \%(18.0-28.0 \%)$ of all cervical rib cases the cervical rib occurred only on one side. In our dataset left-sided unilateral cervical ribs occurred approximately twice as often as right-sided ones ( 39 vs. $22, \chi^{2}$-test, $p=0.02$ ). In the log-linear analysis, the association between major or multiple congenital abnormalities and cervical ribs was not different for unilateral and bilateral cervical ribs (e.g., difference unilateral $\times$ major 0.17 (s.e. 0.39 ), $\chi^{2}=0.1, \mathrm{P}\left[>\chi^{2}\right]=0.75$ ). In addition, we found one unilateral 
rudimentary first rib and one unilateral lumbar rib. In 9.4\% $(2.4-22.5 \%)$ of absent or rudimentary twelfth ribs, these were unilateral.

\section{Small and large Scale Mutations}

Only for a limited set of cases we could get access to cytogenetic analyses. The incidence of cervical ribs in cases of single-gene disorders (e.g. autosomal recessive polycystic kidney disease, cystic fibrosis, osteogenesis imperfecta, campomele dysplasia, chondrodysplasia punctata, split hand/split foot syndrome, Werdnig Hoffmann muscular atropy, Arthrogryposis multiplex; $66.5 \%(46.8-83.1 \%), \mathrm{n}=24)$ is approximately the same (difference test, $\chi^{2}=0.004, \mathrm{p}>0.9$ ) as that for cases with mutations that affect a large part of the genome, such as when a chromosome is absent (monosomy) or supernumerary (trisomy; 63.0\% (49.7 - 75.0\%) in 54 confirmed cases of trisomy, monosomy and triploidy (difference test, $\chi^{2}=0.004, p>0.9$ ). This indicates that a strong association between cervical ribs and congenital abnormalities is not only found when many genes are missing or defect and the association may be due to an interaction of independent events, but also when only one gene is affected and the cervical ribs and other abnormalities are, thus, all pleiotropic effects of that gene. An other conclusion is that many different mutations can lead to cervical ribs, although generally in combination with deleterious pleiotropic effects.

\section{Homeotic transformations of all thoracic vertebrae}

We found that $26.4 \%(21.6-31.8 \%)$ of cervical ribs appear to be accompanied by a homeotic shift of all thoracic vertebrae, indicated by the full, or partial, loss of a rib on the most posterior thoracic vertebra (a posteriorization of the identity of a thoracic into a 
lumbar vertebra, see paragraph Homeotic transformations in the Discussion). Of the rudimentary first ribs (an anteriorization of the first thoracic vertebra) 45.5\% (19.4 $73.5 \%$ ) were associated with a rudimentary rib on the first lumbar vertebra (anteriorization), also pointing to a homeotic shift of all thoracic vertebrae and of the first lumbar vertebra.

\section{DISCUSSION}

We find an extremely high incidence of cervical ribs in deceased fetuses and infants compared to a low incidence in adults. High incidences in deceased fetuses and low incidences in adults have been reported before (Leboucq 1898; Rosenberg 1899; Bardeen 1904; Noback and Robertson 1951; Meyer 1978). This was never related to the constraint on the cervical vertebral number. To the contrary, as an explanation it has been proposed that cervical ribs may disappear by fusing with the vertebra after birth (Chernoff and Rogers 2004). This would imply that $98 \%$ of the cervical ribs disappear before birth (a decrease from 50\% to $1 \%$ ). However, traces of fusion of earlier bony extensions in normal adult seventh vertebrae have, as yet, never been documented. In addition, we found no effect of age on the incidence of cervical ribs accompanying foetal and infant deaths and deceased fetuses as well as deceased infants had cervical ribs in approx. half of the cases. We analysed only two children who died past the age of one (18 and 20 months), but both still had a cervical rib. Furthermore, although there is no good documentation of the incidence of cervical ribs in fetuses and children of the general population, the incidence of cervical ribs in the only study that we found of 
healthy children $(25,949$ healthy, female child-relatives of Tuberculosis patients, Menárguez Carretero and Campo Muňoz 1967) is well within the range found for adults of the general population ( $0.5 \%$ for children versus $0.04-1.07 \%$ for adults, see Table 1$)$. Furthermore, the incidence of cervical ribs in populations of diseased children and adults also appears to be very similar and varies between one and six percent (mainly patients with infections and pulmonary diseases, Davis and King 1939; Schumacher et al. 1992; Mercks et al. 2005 versus Coury and Delaporte 1954; Pionnier and Depraz 1956; Whittaker 1957; Erken 2002). These comparisons do not support a dramatic decrease in incidence of cervical rib frequency during infanthood or childhood. A higher incidence of cervical ribs in children was only found in children with embryonal tumours (Schumacher et al. 1992; Mercks et al. 2005), an association which probably provides further selection against cervical vertebrae (Galis 1999; Galis and Metz 2003). Finally, half of the cervical rib cases in our dataset were not isolated, and were accompanied by posteriorizations of the identity of one or more thoracic vertebrae. This supports our assumption that cervical ribs in fetuses and infants do not indicate normal development of a seventh cervical vertebra with a transiently present rib, but instead represent a homeotic transformation of the seventh cervical vertebra into that of adjacent, rib-bearing, first thoracic vertebra. We conclude, therefore, that the differences between adult and prenatal incidence of cervical ribs are mainly due to early differential mortality of individuals with a cervical rib.

\section{Strong selection against Changes of the Number of cervical Vertebrae}

Our data, thus, indicate very strong selection against changes in the number of cervical vertebrae. The most frequent changes were bilateral and unilateral cervical ribs. 
Rudimentary first ribs were surprisingly rare, but without exception associated with major abnormalities. It is possible that we underestimate the incidence of rudimentary first ribs if they are frequently associated with abnormalities that lead to a very early death, i.e. before the ribs ossify and we can detect them on radiographs. It is also possible that rudimentary first ribs are rarer. This needs further investigation.

We found that selection against changes at the thoraco-lumbar boundary is much weaker than that against a change at the cervico-thoracic one. The number of thoracic vertebrae indeed varies much more amongst mammals than the number of cervical vertebrae (Galis 1999; Narita and Kuratani 2005), attesting to a good agreement between the strength of selection and the apparent evolutionary constraints.

\section{Selection against pleiotropic effects}

It is highly improbable that the mere presence of cervical ribs would lead to fetal or infant deaths. Direct problems related to cervical ribs, compressions of nerves and arteries (thoracic outlet syndrome), usually only appear in adults (Makhoul and Machleder 1992; Roos 1996). Apparently, the constraint on the number of cervical vertebrae should mainly be sought in selection against congenital abnormalities associated with changes of this number (i.e., pleiotropic effects, Galis 1999). Our analysis is in agreement with earlier found associations of cervical ribs with abnormalities (Gladstone and Wakeley 1932; Adson and Coffey 1947; Keeling and Kjaer 1999; Steigenga et al. 2006) and with the absence in our dataset of such an association for rudimentary twelfth ribs. In addition, individuals with cervical ribs that survive infanthood experience on average more cancer than individuals without cervical ribs. There is a significant association of cervical ribs with specific pediatric cancers 
(Schumacher et al. 1992; Mercks et al. 2005; see also Galis and Metz 2003). The multitude of deleterious pleiotropic effects dramatically limits the chances of individuals with cervical ribs to develop into viable adults.

\section{Homeotic transformations}

Homeotic transformations were first described by Bateson (1894) and are transformations of the identity of one structure into that of another. A well-known example is the transformation of the antennae of insects into legs as a result of antennapedia mutations (Abbott and Kaufman 1986). Cervical ribs appear to be partial, or complete, homeotic transformations of the seventh cervical vertebrae into rib-bearing thoracic vertebrae, i.e. a posteriorization of the identity. Fishel (1906) and Leboucq (1898) found that vertebrae with a cervical rib usually display more shape characteristics of thoracic vertebrae than the mere presence of a rib. In addition, Fishel (1906) and Oostra et al. (2005) conclude that in the majority of cases cervical ribs are not isolated events, but are accompanied by homeotic changes of several adjacent cervical and thoracic vertebrae. In agreement with their observation, we found that approximately one quarter of cervical ribs appear to be accompanied by a homeotic shift of all thoracic vertebrae. In addition, a similar proportion of cervical ribs is unilateral and these tend to be accompanied by a larger first thoracic rib on that side than on the contralateral side, indicating a partial homeotic change of the first thoracic vertebra into that of the more posterior second thoracic vertebra. Of the rudimentary first ribs (an anteriorization of the first thoracic vertebra) at least $20 \%$ appear to be associated with a homeotic shift of all thoracic vertebrae and of the first lumbar vertebra. 
The Hox genes appear to be essential mediators of the anterior-posterior patterning of the presomitic mesoderm of the cervico-thoracic region and, hence, to be involved in homeotic changes of vertebral identity (Gaunt 1994; Burke et al. 1995, Cohn and Tickle 1999; Stern et al. 2006). The expression of Hox genes involved in this patterning is spatially and temporally co-linear and highly conserved (the zootype of Slack et al. 1993, see also de Rosa et al. 1999, Stern et al. 2004). Our data suggest that mutations with an effect on the conserved expression of these genes during the anterior-posterior patterning of the paraxial mesoderm may be common, but are strongly selected against.

\section{Left-right asymmetry}

In nearly a quarter of all cervical rib cases the cervical rib occurred only on one side, predominantly on the left side. Interestingly, this suggests that these cervical ribs are caused by a diminished coordination between the development of the left and right somites. Asymmetric left-right somite formation has recently been induced by deficient retinoic acid signaling in mice, chickens and zebrafishes (Vermot and Pourquié 2005; Kawakami et al. 2005; Vermot et al. 2005). Asymmetric somite formation was correlated with and presumably due to asymmetric somitic clock expression. In mice deficient signalling led to an acceleration in the development of the left somites compared to the right ones, with the asymmetry most prominent in the somites around the cervico-thoracic boundary (Vermot et al. 2005). A unilateral cervical rib in human fetuses and infants may similarly be the result of an acceleration of somitogenesis in the somites on the side of the rib (usually the left!) leading to a differential expression of the Hox genes that mediate anterior-posterior identity. In our dataset left-sided unilateral cervical ribs occurred approximately twice as frequently as right-sided ones. The left- 
right asymmetries in vertebrae were never accompanied by other left-right asymmetries, such as asplenia, abnormal lung lobation and intestinal malrotation. This pattern is in full agreement with the independence found in mice and zebrafishes for the left-right symmetric development of the somites and the left-right asymmetry of internal organs (Vermot and Pourquié 2005; Kawakami et al. 2005).

\section{Interactivity during the early patterning of the anterior-posterior axis}

The determination of the position of the cervico-thoracic boundary mediated by the Hox genes forms part of the early anterior-posterior patterning of the presomitic mesoderm during the early neurula stage (e.g. Gaunt 1994; Burke et al. 1995; Cohn and Tickle 1999; Chernoff and Rogers 2004; Stern et al. 2006). The fact that more than half of all fetal and infant deaths come with cervical ribs emphasizes once again the vulnerability of the early organogenesis, or neurula stage (Galis and Metz 2003). The association of cervical ribs with multiple and with major abnormalities in other parts of the body (see Table 4) moreover points at the interaction of the early anterior-posterior patterning of the paraxial mesoderm with many other patterning processes and many morphogenetic processes. Corroboration for this viewpoint is, firstly, provided by grafting experiments in which the anterior-posterior position of paraxial mesoderm was changed and which led to changes in a) the anterior-posterior patterning of the adjacent neuroepithelium (Bel-Vialar 2002; see also Grapin-Botton et al. 1997; Ensini et al. 1998), b) the timing of the migration of neural crest cells (Sela-Donenfeld and Kalcheim 2000) and c) the initiation and outgrowth of the limbs (Saito et al. 2006). Secondly, this viewpoint is corroborated by experiments in which two processes that are involved in the determination of the anterior-posterior patterning of paraxial mesoderm were 
manipulated: the opposing and antagonistic gradient of Fgfs, Wnts and RA and the oscillatory gene expression (somatic clock) in the paraxial mesoderm. These experiments have demonstrated couplings of the anterior-posterior patterning of paraxial mesoderm with morphogenetic processes such as proliferation and axial lengthening (Dubrulle et al. 2001; Dubrulle and Pourquié 2004), somitogenesis (Zakany et al. 2001; Dubrulle et al. 2001), convergent extension (Ninomiya et al. 2004, see also Mathis et al. 2001) and cell migration (Yang et al. 2001), as well as with patterning along the other embryonic axes, i.e. left-right and midline patterning (Raya et al. 2004, Krebs et al. 2003 see also Yamamoto et al. 2003 and Latimer et al. 2002) and dorsoventral patterning (Diez del corral et al. 2003). There is thus a wealth of data supporting the strong coordination of the patterning of the three embryonic axes in the three adjacent germ-layers with a central role of the mesoderm in this process (see also Kumar et al. 2003) and, additionally, there is strong support for a coupling between patterning and morphogenetic processes.

The determination of the thoraco-lumbar boundary occurs later than that of the cervico-thoracic boundary. The lower frequency of shifts of this boundary suggests that this determination is less vulnerable. A lower interactivity is suggested by the absence of a significant association between shifts of this boundary and congenital abnormalities. The supposedly lower interactivity and vulnerability of this later stage at which the number of thoracic vertebrae is determined is a potential explanation for the weaker evolutionary constraint on changes of the number of thoracic vertebrae. 


\section{Modularity, stabilizing Selection and Conservation}

The number of cervical vertebrae is determined during the early organogenesis stage (also referred to as phylotypic stage) that is itself strongly conserved in mammals (for a review see Hall 1999, but see Richardson et al. 1997). Sander (1983) and Raff (1994) proposed that the high interactivity between modules is the major cause of conservation in this stage. This high interactivity causes mutations to have negative pleiotropic effects that become amplified as development proceeds. Conservation is a consequence of consistently strong stabilizing selection against mutations via their pleiotropic effects. We earlier found support for the validity of this hypothesis in an analysis of teratological studies in rodents (Galis and Metz 2001). We found that chemical and other disturbances of this stage (phenocopies of mutations) lead to a considerably higher mortality than disturbances of earlier and later developmental stages. From the pattern of multiple induced abnormalities (pleiotropic effects), we concluded that it is the high interactivity and low effective modularity that is the root cause of the vulnerability of the stage: a particular, potentially useful change almost always will induce lethality even before the organism is exposed to ecological selection.

During early organogenesis the organ primordia make their first appearance. Hence the evolutionary conservation of early organogenesis in mammals may well be implicated in the conservation of the number of repeated organs (eyes, ears, vertebrae, limbs and digits; for the latter, see e.g. Galis et al. 2002). The present study indeed strongly suggests that during organogenesis the high interactivity and low modularity of the patterning of the anterior-posterior axis in the cervical paraxial mesoderm appears to be the root cause for the selective early deaths of humans with a changed number of 
cervical vertebrae. Mutations that change the number of cervical vertebrae almost always appear to have many negative pleiotropic effects that cause mortality in fetuses and infants.

Low effective modularity, pleiotropic effects and strong selection, thus, appear to be important for both the conservation of the number of cervical vertebrae, as well as that of the entire stage during which this is determined. This implies that the evolutionary constraint on changes of early organogenesis, including changes of the number of cervical vertebrae, derives at least in part from a developmental constraint (Maynard Smith et al. 1985; Amundsen 1994; Schwenk and Wagner 2003; Arthur 2004; Amundson 2005). The developmental constraint is not a constraint in the sense that there is no production of mutational variation for the number of cervical vertebrae (i.e., a constraint of the 'forbidden morphologies' type), but in the sense that the development of this variation is accompanied, sheer unavoidably, by the development of variation in other traits that dramatically reduces the fitness. We are, thus, dealing with so-called pleiotropic constraints biasing the response to selection to an extent that it leads to evolutionary stasis (Hansen and Houle 2004).

Opitz et al. (1987) have argued that humans continue to be exposed to strong internal (i.e., not ecologically mediated) selection, for instance selection against supernumerary digits, cyclopia and other abnormalities $(88.9 \%$ and $97.7 \%$ dead at the time of birth). Our results extend their conclusion to changes in the number of cervical vertebrae. Thus, strong natural selection in humans still occurs prenatally and it appears to play a major role in the conservation of at least one aspect of our body plan. The strong selection against changes of early organogenesis in rodents (Galis and Metz 2003) and against supernumerary digits in humans (Opitz et al. 1987), implicates internal selection to be of more general importance for the conservation of our common body plan. 
As a final conclusion we wish to draw the attention to the fact that changes of highly conserved traits of the body plan, such as the number of cervical vertebrae, may well be useful as indicators of medical risks (Steigenga et al. 2006).

\section{ACKNOWLEDGEMENTS}

We thank Jaap van Veldhuisen and Ron Otsen of the photography division of the Institute of Pathology of the Free University Medical Centre (VUMC) for high quality radiographs and the photograph of Figure 2, Adriana Gittenberger-de Groot and Alain Kummer for valuable discussions and Jacques van Alphen, Ricardo Azevedo, Jonathan Cooke, Thomas Hansen, Carolien de Kovel, Mohammed Noor and Roelof-Jan Oostra for insightful comments on the manuscript. This work was supported in part by the Netherlands Science Foundation (N.W.O.) with a Veni grant to TVD.

\section{LITERATURE CITED}

Abbott, M.K., and T.C. Kaufman. 1986. The relationship between the functional complexity and the molecular organization of the Antennapedia locus of Drosophila melanogaster. Genetics 114: 919-942.

Adson, A.W., and J.R. Coffey. 1947. Cervical rib. Ann. Surg. 85: 839-857.

Agresti, A. 2002. Categorical Data Analysis (2nd Edition). Wiley.

Akaike, H. 1973. Information theory and an extension of the maximum likelihood principle. In Second International Symposium on Information Theory, B.N. Petrov and F. Csaki (eds.), Academiai Kiado, Budapest, 267-281. 
Amundson, R. 1994. Two Concepts of Constraint: Adaptationism and the Challenge from Developmental Biology. Phil. Sci.61: 556-578.

Amundson, R. 2005. The Changing Role of the Embryo in Evolutionary Thought: Roots of Evo-Devo. Cambridge University Press, Cambridge, U.K.

Ancel, P., and L. Sencert. 1902. De quelques variations dans la nombre des vertèbres chez l'homme leur interpretation. J. de l'Anat. et Physiol. 38: 218-257.

Arthur, W. 2004. Biased embryos and evolution. Cambridge University Press, Cambridge, U.K.

Bardeen, Ch.R. 1904. Numerical vertebral variation in the human adult and embryo. Anat. Anz. 25: 497-519.

Bateson, W. 1894. Materials for the study of variation, MacMillan, London.

Bell-Vialar S., N. Itasaki, and R. Krumlauf. 2002. Initiating Hox gene expression: in the early chick neural tube differential sensitivity to FGF and RA signalling subdivides the HoxB genes in two distinct groups. Development 129: 5103-5115.

Berner, F. 1944. über Rippenanomalien auf Grund von 6 Millionen Reihenbildern. Fortschr. Röntgenstr. 69: 202-221.

Bianchi, S. 1894. Sulla frequenza della anomalie numeriche vertebrali nello scheletro dei normali e degli alienati. Atti della R.. Accad. Dei Fisiocritici in Siena 7: 21-31.

Burke, A.C., C.E. Nelson, B.A. Morgan, and C. Tabin. 1995. Hox genes and the evolution of vertebrate axial morphology. Development 121: 333-346.

Cartlidge, P.H.T., and J.H. Stewart. 1995. Effect of changing the stillbirth definition on evaluation of perinatal mortality rates. Lancet 346: 486-488. 
Chernoff, N., and J.M. Rogers. 2004. Supernumerary ribs in developmental toxicity bioassays and in human populations: incidence and biological significance. J. Toxicol. Environ. Health B. Crit. Rev. 7: 437-49.

Cohn, M.J., and C. Tickle. 1999. Developmental basis of limblessness and axial patterning in snakes. Nature 399: 474-479.

Coury, C., and J. Delaporte. 1954. Les anomalies congenitales des côtes. Sem. Hop. Paris: $2656-2673$.

Crimm, P.D. 1952. Evaluation of a five year minifilm program. Am. J. Roentg. 68: 240246.

Cuvier, G. 1835. Leçons d' anatomie comparée. Tome premier, $2^{\text {nd }}$ Edn. Crochard, Paris.

Davidson, A. J., Ernst, P., Wang, Y., Dekens, M. P., Kingsley, P. d., Palis, J. Korsmeyer, S. J., Daley G. Q., and Zon L. I. 2003. cdx4 mutants fail to specify blood progenitors and can be rescued by multiple hox genes. Nature 425: 300-306.

Davis, D.B., and J.C. King. 1939. Cervical rib in early life. Am. J. Diseases Children 56: 744-755.

De Galan-Roosen, A.E.M, J.C. Kuijpers, A.P. Meershoek, and D. van Velzen. 1998. Contribution of congenital malformations to perinatal mortality. A 10 years prospective regional study in The Netherlands, Eur. J. Obstet. Gyn. Reprod. Biol. 80: 55-61.

De Rosa, R., J. K. Grenier, J. Andreeva, C.E. Cook, A. Adoutte, M. Akam, S. B. Carroll, and G. Balavoine. 1999. Hox genes in brachiopods and priapulids and protostome evolution. Nature 399: 772-776. 
Diez del Corral, R., I. Olivera-Martinez, A. Goriely, E. Gale, M. Maden, and K. Storey 2003. Opposing FGF and retinoid pathways control ventral neural pattern, neuronal differentiation, and segmentation during body axis extension. Neuron 40: 65-79.

Dubrulle, J., McGrew, M. J., and O. Pourquié. 2001. FGF signaling controls somite boundary position and regulates segmentation clock control of spatiotemporal Hox gene activation. Cell 106: 219-232.

Dubrulle J., and O. Pourquié. 2004. fgf8 mRNA decay establishes a gradient that couples axial elongation to patterning in the vertebrate embryo. Nature 427: 419422.

Ensini, M., Tsuchida, T. N., Belting, H.-G., and T. M. Jessell. 1998. The control of rostrocaudal pattern in the developing spinal cord: specification of motor neuron subtype identity is initiated by signals from paraxial mesoderm. Development 125 : 969-982.

Erken, E., H.T.E. Ozer, B. Gulek, B., and B. Durgun. 2002. The association between cervical rib and sacralization. Spine 27: 1659-1664

Etter, L.E. 1944. Osseous abnormalities of the thoracic cage seen in forty thousand consecutive chest photoroentgenograms. Am. J. Roentg. 5: 359-363.

Eurocat Update to Report 7. 1999. Prevalence of Congenital Anomalies in Europe 19956, Brussels.

Fishel, A. 1906. Untersuchungen über die Wirbelsäule und den Brustkorb des Menschen. Anatomische Hefte 31: 462-588.

Flower, W.H., and R. Lydekker 1891. The study of mammals. Adam and Charles Black, London. 
Galis, F. 1999. Why do almost all mammals have seven cervical vertebrae?

Developmental constraints, Hox genes and Cancer. J. exp. Zool. B. (Mol. Dev. Evol.) 285: $19-26$.

Galis, F., J.A.J. Metz, and J.J.M. van Alphen 2002. Why five fingers? Evolutionary constraints on digit numbers. Trends Ecol. Evol. 16: 637-646.

Galis F., and J.A.J. Metz. 2003. Testing the vulnerability of the phylotypic stage. BioEssays 25: 1035-1039.

Gaunt, S.J. 1994. Conservation in the Hox code during morphological evolution. Int. J. dev. Biol. 38: 549-552.

Gladstone, R.J., and C.P.G. Wakeley. 1932. Cervical ribs and rudimentary first thoracic ribs considered from the clinical and etiological standpoints. J. Anat. 66: 334-337. Grapin-Botton, A., Bonnin, M.-A., and N.M. LeDouarin. 1997. Hox gene induction in the neural tube depemds on three parameters: competence, signal supply and paralogue group. Development 124: 849-859.

Hall, B.K. 1999. Evolutionary developmental biology, 2nd edition, Kluwer Academic Press, Dordrecht.

Hansen, T. F., and D. Houle. 2004. Evolvability, stabilizing selection, and the problem of stasis. Pp. 130-150 in M. Pigliucci, and K. Preston, eds. Phenotypic integration: Studying the ecology and evolution of complex phenotypes. Oxford University Press, Oxford.

Henderson, M.S. 1913. Cervical rib. Report of thirty-one cases. Am. J. Orthop. Surg. 11: 408-430. 
Kawakami Y., A. Raya, R.M. Raya, C. Rodriguez-Esteban, and J.C. Belmonte. 2005. Retinoic acid signalling links left-right asymmetric patterning and bilaterally symmetric somitogenesis in the zebrafish embryo. Nature 435:165-171.

Keating, D.R., and J.R. Amberg.1954. A course of potential error in the roentgen diagnosis of cervical ribs. Radiology 62: 688-694.

Keeling, J.W., and I. Kjaer. 1999. Cervical ribs: useful marker of monosomy X in fetal hydrops. Pediat. Devel. Pathol. 2: 119-123.

Krebs, L. T., Iwai, N., Nonaka, S., Welsh, I. C., Lan Y. Jiang, R., Saijoy, Y., O’Brien T. P., Hamada H., and T. Gridley. 2003. Notch signalling regulates left-right asymmetry determination by inducing Nodal expression. Genes Dev. 17: 12071212.

Kumar M., N. Jordan, D. Melton, and A. Grapin-Botton. 2003. Signals from lateral plate mesoderm instruct endoderm toward a pancreatic fate. Dev Biol. 259: 109-22.

Lancaster, P. and E. Pedisich. 1995. Congenital Malformations Australia 1981-1992. Australian Institute of Health and Welfare, National Perinatal Statistics Unit.

Lanier, R.R.1944. Length of first, twelfth, and accessory ribs in american whites and negroes; their relationship to certain vertebral variations. Am. J. Physical. Anthropol. Eurocat Report 7. 1997. 15 Years of Surveillance of Congenital Anomalies in Europe 1980-1994”, Scientific Institute of Public Health, Brussels.

Latimer, A. J., Dong, X., Markov, Y., and Appel, B. 2002. Delta-Notch signaling induces hypochord development in zebrafish, Development 129: 2555-2563.

Leboucq, H. 1898. Recherches sur les variations anatomiques de la première côte chez l'homme. Arch. Biol. 15: 9-178. 
Makhoul, R.G., and H.I. Machleder. 1992. developmental anomalies at the thoracic outlet: an analysis of 2000 consecutive cases. J. Vasc. Surg. 16, 534-545.

Mathis, L., Kulesa, P. M. and S. E. Fraser. 2001. FGF receptor signalling is required to maintain neural progenitors during Hensen's node progression. Nat. Cell Biol. 3: $559-566$.

Maynard Smith, J., R. Burian, S. Kauffman, P. Alberch, J. Campbell, B. Goodwin, R. Lande, D. Raup, and L. Wolpert. 1985. Developmental constraints and evolution. Quart. Rev. Biol, 60:265-287.

McNally, E., B. Sandin, and R.A. Wilkins. 1990. The ossification of the costal element of the seventh cervical vertebra with particular reference to cervical ribs. J. Anat. 170: $125-129$.

Menárguez Carretero, L., and M. Campo Muňoz.1967. Estudio radiologico y tipos morfologicos de costillas cervicales en el sexo femenino. Enferm. Torax 16: 285308.

Merks, J.H.M., C.D. van Karnebeek, H.N. Caron, and R.C. Hennekam. 2003. Phenotypic abnormalities: terminology and classification. Am. J. Med. Genet. 123A: 211-230.

Merks, J.H.M., A.M. Smets, R.R. van Rijn, J. Kobes, H.N. Caron, M. Maas, R.C. Hennekam 2005. Prevalence of rib anomalies in normal Caucasian children and childhood cancer patients. Eur. J. Med. Genet. 48:113-129.

Meyer D.B. 1978. The appearance of 'cervical ribs' during early human fetal development. Anat. Rec. 190: 481. 
Narita,Y, and S. Kuratani. 2005. Evolution of the vertebral formulae in mammals: a perspective on developmental constraints.. J Exp Zool B Mol Dev Evol. 304: 91106.

Ninomiya, H., Elinson, R.P., and Winklbauer, R. 2004. Antero-posterior tissue polarity links mesoderm convergent extension to axial patterning. Nature 430: 364-367.

Noback C.R., and G.G. Robertson. 1951. Sequences of appearance of ossification centers in the human skeleton during the first five prenatal months. Am. J. Anat. 89: $1-28$.

Nolte, E., A. Brand, I. Koupilova, and M. McKee. 2000. Neonatal and postneonatal mortality in Germany since unification. J. Epidem. Commun. Health 54: 84-90.

Oostra R.J., R.C. Hennekam L. de Rooij L., and A.F. Moorman. 2005. Malformations of the axial skeleton in Museum Vrolik I: homeotic transformations and numerical anomalies. Am. J. Med. Genet. A. 134: 268-281.

Opitz, J.M., J.M. Fitzgerald, J.F. Reynolds, S.O. Lewin, A. Daniel, L.S. Ekblom, and S. Philips. 1987. The Montana fetal genetic pathology program and a review of prenatal death in humans. Am J. Med. Genet. Suppl. 3: 93-112.

Paterson, A.M. 1893. in Bardeen (1904).

Pionnier, R. A. Depraz 1956. Les anomalies costales d'origine congénital (Etude statistique d'après 10000 radiographies). Radiol. clin. 25, 170-186.

Raff, R.A. 1994. Developmental mechanisms in the evolution of animal form: origins and evolvability of body plans. Pp. 489-500 in S. Bengston, ed. Early life on Earth. Columbia University Press, New York. 
Raya A., Y. Kawakami, C. Rodriguez-Esteban, M. Ibanes, et al. 2004. Notch activity acts as a sensor for extracellular calcium during vertebrate left-right determination. Nature 427: 121-128.

Richardson, M.K., J. Hanken, M.L. Gooneratne, C. Pieau, A. Raynaud, L. Selwood, and G.M. Wright 1997. There is no highly conserved embryonic stage in the vertebrates: implications for current theories of evolution and development. Anat. Embryol. 196: 91-106.

Roos, D.B. 1996. Historical perspectives and anatomic considerations. Semin. Thorac. Cardiovas. Surg. 8:183-189.

Rosenberg, E. 1899. Über eine primitive From der Wirbelsäule des Menschen. Morphol. Jahrbuch 27: 1-118.

Regan, L., P.R. Braude, and P.L. Trembath 1989. Influence of past reproductive performance on risk of spontaneous abortion. British Med. J. 299: 51-545.

Saito, D., Yonei-Tamura, S., Takahashi, Y., and K. Tamura. 2006. Level-specific role of paraxial mesoderm in regulation of Tbx5/Tbx4 expression and limb initiation. Dev. Biol. 292: 79-89.

Sander, K. 1983. The evolution of patterning mechanisms: gleanings from insect embryogenesis and spermatogenesis. Pp. 137-159 in B.C. Goodwin, N. Holder, and, C.C. Wylie, eds. Cambridge University Press, Cambridge.

Saraiya, M. et al. 1999. Estimates of the annual number of clinically recognized pregnancies in the United States, 1981-1991. Am. J. Epidemiology 149: 1025-1029.

Schumacher, R., A. Mai and P. Gutjahr. 1992. Association of rib anomalies and malignancy in childhood. Eur. J. Pediatr. 151: 432-434. 
Schwenk, K., and G.P. Wagner 2003. Constraint. in Keywords and Concepts in Evolutionary Developmental Biology. B.K. Hall and W. M. Olson, eds. Harvard University Press, Cambridge M.A..

Sela-donenfeld, D., and C. Kalcheim 2000. Inhibition of noggin expression in the dorsal neural tube by somitogenesis: a mechanism for coordinating the timing of neural crest emigration. Development 127: 4845-4854.

Simpson, E.H. 1951. The interpretation of interaction in contingency tables. J. Royal Stat. Soc. Series B 13: 238-241.

Slack, J.M., P.M.Holland, C.F. and Graham 1993. The zootype and the phylotypic stage. Nature 361: 490-492.

Southam, A.H., and O.B.E. Bythell.1924. Cervical ribs in children. Brit. Med. J. Nov. 8: $844-845$.

Staderini, R. 1894. In Bardeen (1904).

Steigenga, M.J., F.M. Helmerhorst, J. de Koning, A.M.I. Tijssen, S.A.T. Ruinard, and F. Galis, 2006. Evolutionary conserved structures as indicators of medical risks: increased incidence of cervical ribs after ovarian hyper stimulation in mice. J. Anim. Biol. 56: 63-68.

Steinbach 1889. In Bardeen (1904).

Stern, C.D., et al. 2006. Head-tail patterning of the vertebrate embryo: one, two or many unresolved problems? Int. J. Dev. Biol. 50:3-15.

Sycamore, L.K. 1944. Common congenital anomalies of the bony thorax. Am. J. Roentg. 51:593-599.

Topinard, P. 1877. Des anomalies de nombre de la colonne vertébrale chez l'homme. Rev. de 1. Anthropol. 6: 575-659. 
Van Duin, C. 2002. Hogere zuigelingensterfte in minder welvarende gebieden en onder niet-westerse allochtonen in Nederland. Maandstatistiek van de bevolking, CBS (Central Registry for Statistics, the Netherlands) 50: 4-6.

Venables, W. N. and, B.D. Ripley 2002. Modern Applied Statistics with S (4th Edn.). Springer-Verlag, New York.

Vermot, J., O. Pourquié 2005. Retinoic acid coordinates somitogenesis and left-right patterning in vertebrate embryos. Nature 435: 215-220.

Vermot J. et al. 2005. Retinoic acid controls the bilateral symmetry of somite formation in the mouse embryo. Science 308: 563-566.

Whittaker, L.R. 1957. The incidence of cervical rib in African patiens. East Afr. Med. J. 34: 144-147.

Yamamoto, M., Mine, N., Mochida, K., Sakai, Y., Saijoh, Y., Meno, C., and H.

Hamada. 2003. Nodal signaling induces the midline barrier by activating Nodall expression in the lateral plate. Development 130: 1794-1804.

Yang, X., Dormann, D., Muensterberg, A. E., and C.J. Weijer. 2002. Cell movement patterns during gastrulation in the chick are controlled by positive and negative chemotaxis mediated by FGF4 and FGF8. Developmental Cell 3: 425-437.

Zakany, J., Kmita, M., Alarcon, P., de la Pompa J. L., and D. Duboule. 2001. Localized and transient transcription of Hox genes suggests a link between patterning and the segmentation clock. Cell 106: 207-217. 
Table 1. Rib variation frequencies in the general population. Studies are of two types, either based on radiographies that were made for Tuberculosis-prevention, or based on collections of dried skeletons.

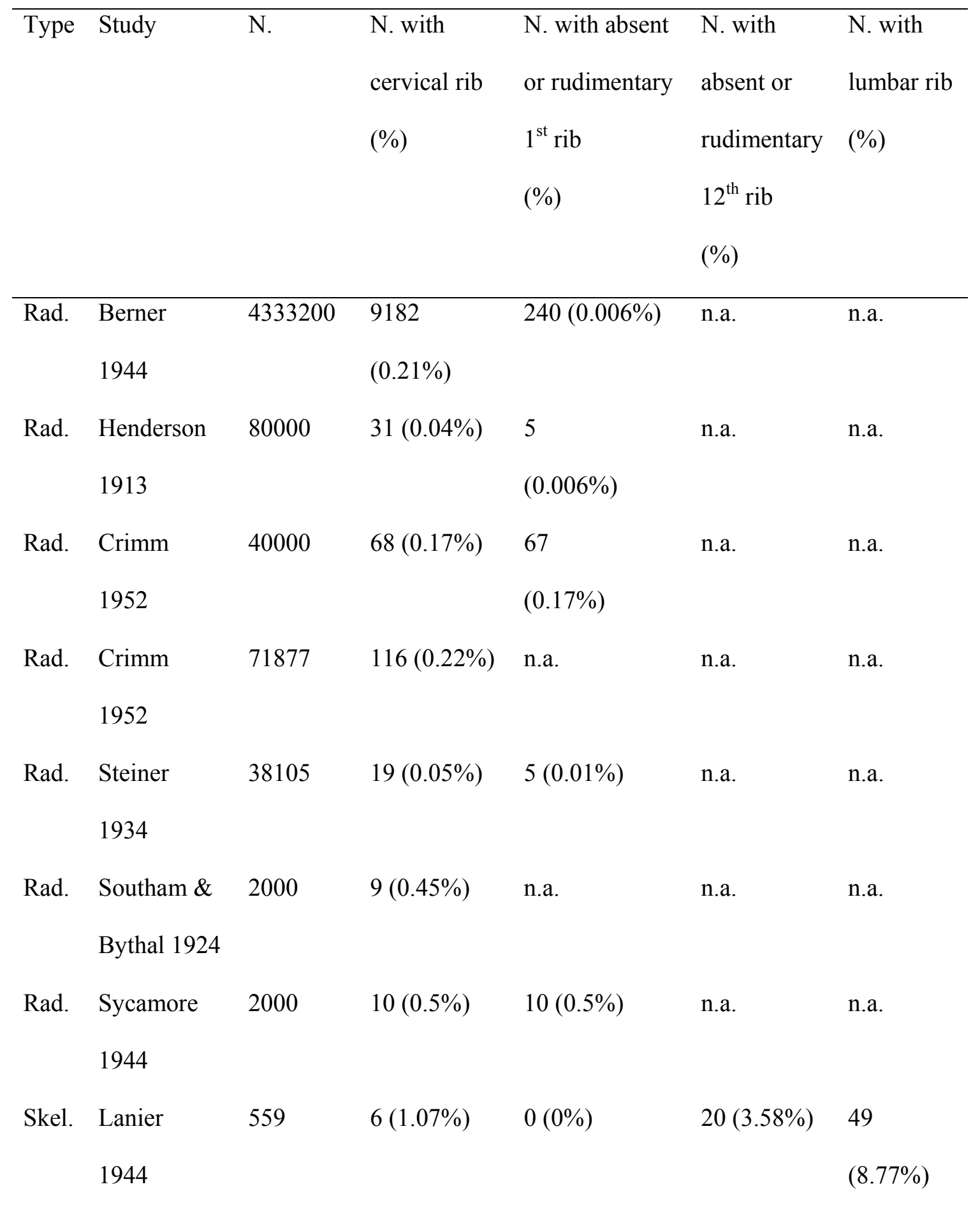




\begin{tabular}{|c|c|c|c|c|c|c|}
\hline Skel. & $\begin{array}{l}\text { Fishel } \\
1906\end{array}$ & 524 & $5(0.95 \%)$ & n.a. & n.a. & n.a. \\
\hline Skel. & $\begin{array}{l}\text { Topinard } \\
1877\end{array}$ & 350 & $2(0.57 \%)$ & $0(0 \%)$ & $5(1.43 \%)$ & $\begin{array}{l}2 \\
(0.006 \%)\end{array}$ \\
\hline Skel. & $\begin{array}{l}\text { Paterson } \\
1893\end{array}$ & 132 & $0(0 \%)$ & $0(0 \%)$ & $2(1.52 \%)$ & $1(0.76 \%)$ \\
\hline Skel. & $\begin{array}{l}\text { Bianchi } \\
1894\end{array}$ & 130 & $0(0 \%)$ & $0(0 \%)$ & 5 & 3 \\
\hline Skel. & $\begin{array}{l}\text { Staderini } \\
1894\end{array}$ & 100 & $1(1 \%)$ & $0(0 \%)$ & $6(6 \%)$ & $2(2 \%)$ \\
\hline Skel. & $\begin{array}{l}\text { Steinbach } \\
1889\end{array}$ & 83 & $0(0 \%)$ & $0(0 \%)$ & $1(1.20 \%)$ & $3(3.61 \%)$ \\
\hline Skel. & $\begin{array}{l}\text { Bardeen } \\
1904\end{array}$ & 70 & $0(0 \%)$ & $0(0 \%)$ & $4(5.71 \%$ & $3(4.29 \%)$ \\
\hline Skel. & $\begin{array}{l}\text { Ancel \& } \\
\text { Sancert } \\
1902\end{array}$ & 43 & $0(0 \%)$ & $0(0 \%)$ & $1(2.33 \%)$ & $3(6.98 \%)$ \\
\hline
\end{tabular}

Abbreviations: Rad.-radiographs, Skel.-dried skeletons, n.a.-not available. 
Table 2. Selection against cervical ribs.

\begin{tabular}{|c|c|c|c|c|c|c|}
\hline $\begin{array}{l}\text { Age } \\
\text { Class } \\
i\end{array}$ & $\mu_{\mathrm{i}}$ & $\begin{array}{l}\text { Survival } \\
\text { up to } \\
\text { age } i\end{array}$ & $\begin{array}{l}\text { Prevalence } \\
\text { among those } \\
\text { that died } p_{\mathrm{i}}\end{array}$ & $\begin{array}{l}\text { Prevalence } \\
P_{\mathrm{i}}\end{array}$ & $\begin{array}{l}\text { Relative } \\
\text { survival up to } \\
\text { age } i \text { with } \\
\text { cervical ribs } \\
S_{\mathrm{Ri}}\end{array}$ & $\begin{array}{l}\text { Relative } \\
\text { survival up to } \\
\text { age } i \text { without } \\
\text { cervical ribs } \\
S_{\text {NORi }}\end{array}$ \\
\hline 0 & 0.15 & 1 & 0.505 & 0.097 & 1 & 1 \\
\hline 1 & 0.01 & 0.85 & 0.505 & 0.025 & 0.218 & 0.918 \\
\hline 2 & 0 & 0.8415 & 0.020 & 0.020 & 0.174 & 0.913 \\
\hline 3 & 1 & 0.8415 & 0.020 & 0.020 & 0.174 & 0.913 \\
\hline
\end{tabular}

Table 3. Selection against absent or reduced twelfth thoracic ribs

\begin{tabular}{|l|l|l|l|l|l|l|}
\hline Age & $\mu_{\mathrm{i}}$ & Survival & Prevalence & Prevalence & Relative & Relative \\
Class & & up to & among those & $P_{\mathrm{i}}$ & survival up to & survival up to \\
age $i$ with $12^{\text {th }}$ & that died $p_{\mathrm{i}}$ & & $\begin{array}{l}\text { age } i \text { without } \\
\text { thoracal ribs } \\
12^{\text {th }} \text { thoracal } \\
\text { ribs } S_{\mathrm{NOR}}\end{array}$ \\
\hline 0 & 0.15 & 1 & 0.077 & 0.031 & 1 & 1 \\
\hline 1 & 0.01 & 0.85 & 0.077 & 0.022 & 0.624 & 0.857 \\
\hline 2 & 0 & 0.8415 & 0.022 & 0.022 & 0.603 & 0.849 \\
\hline 3 & 1 & 0.8415 & 0.022 & 0.022 & 0.603 & 0.849 \\
\hline
\end{tabular}


Table 4. Frequent congenital abnormalities in deceased human fetuses and infants $(>10$ cases) and associated changes in the number of cervical vertebrae.

\begin{tabular}{|c|c|c|c|c|}
\hline $\begin{array}{l}\text { Congenital } \\
\text { abnormality }\end{array}$ & $\begin{array}{l}\text { N. of } \\
\text { cases }\end{array}$ & $\begin{array}{l}\text { N. with cervical rib } \\
(\%)\end{array}$ & $\begin{array}{l}\mathrm{N} \text { with absent or } \\
\text { rudimentary first rib (\%) }\end{array}$ & $\begin{array}{l}\mathrm{N} \text { with aberrant number } \\
\text { of cervical vertebrae }(\%)\end{array}$ \\
\hline Cleft lip/palate & 12 & $6(50 \%)$ & $3(25 \%)$ & $9(75 \%)$ \\
\hline Horseshoe kidney & 10 & $8(80 \%)$ & $1(10 \%)$ & $9(90 \%)$ \\
\hline Bleeding disorders & 98 & $68(69.4 \%)$ & $1(1 \%)$ & $70(70.4 \%)$ \\
\hline Oligo/polydactyly & 17 & $9(52.9 \%)$ & $4(23.5 \%)$ & $13(76.4 \%)$ \\
\hline Spina bifida & 10 & $4(40 \%)$ & $1(10 \%)$ & $5(50 \%)$ \\
\hline Aberrant Arteria & 22 & $18(81.8 \%)$ & $0(0 \%)$ & $18(81.8 \%)$ \\
\hline Subclavia dextra & & & & \\
\hline Ventricular & 31 & $17(54.8 \%)$ & $8(25.9 \%)$ & $25(80.7 \%)$ \\
\hline septum defect & & & & \\
\hline $\begin{array}{l}\text { Transfusion } \\
\text { syndrome }\end{array}$ & 14 & $8(57.1)$ & $0(0 \%)$ & $8(57.1 \%)$ \\
\hline $\begin{array}{l}\text { Left-right } \\
\text { disorders }\end{array}$ & 21 & $15(71.4 \%)$ & $1(4.8 \%)$ & $16(76.2 \%)$ \\
\hline $\begin{array}{l}\text { Bilateral kidney } \\
\text { agenesis }\end{array}$ & 10 & $6(60 \%)$ & $1(10 \%)$ & $7(70 \%)$ \\
\hline Spina bifida & 11 & $5(45.5 \%)$ & $1(9.1 \%)$ & $6(54.6 \%)$ \\
\hline Anal atresia & 11 & $6(54.5 \%)$ & $3(27.3 \%)$ & $9(81.8 \%)$ \\
\hline Hydrops foetalis & 22 & $10(45.5 \%)$ & $1(4.5 \%)$ & $11(50 \%)$ \\
\hline Dysmaturity & 59 & $33(55.9 \%)$ & $0(0 \%)$ & $33(55.9 \%)$ \\
\hline Prematurity & 68 & $39(57.4 \%)$ & $2(2.9 \%)$ & $41(60.3 \%)$ \\
\hline
\end{tabular}




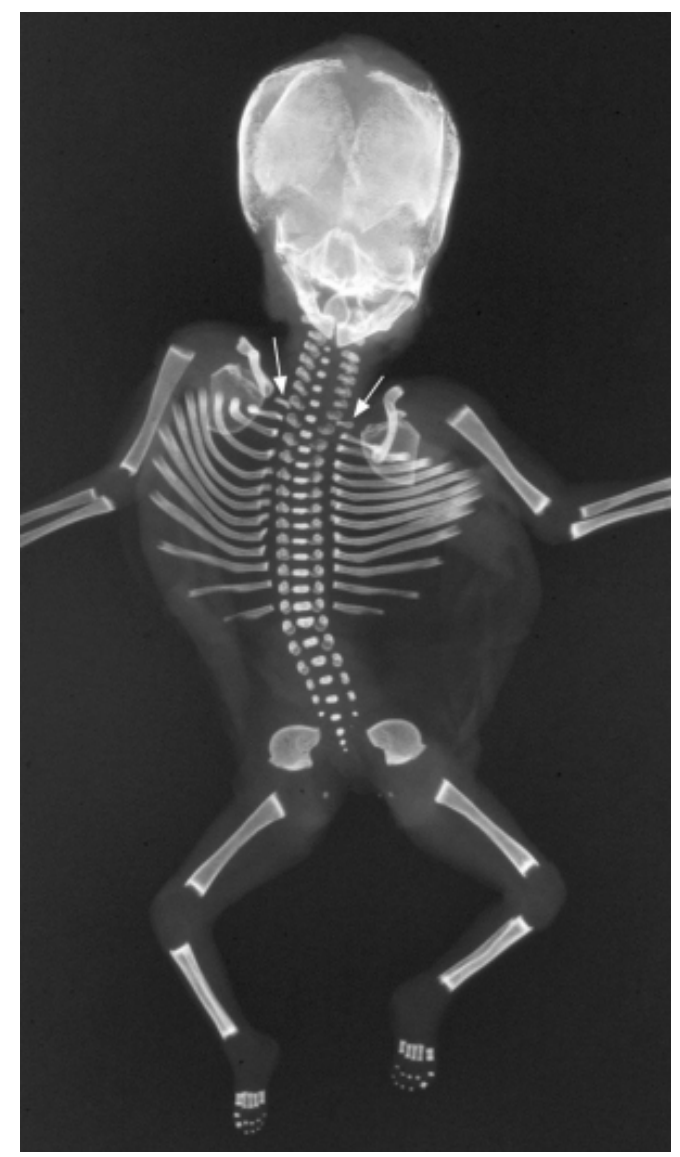

Figure 1. Radiograph showing left and right rudimentary cervical ribs in a male fetus of 16 weeks of gestation. Arrows indicate cervical ribs. To enhance the visibility of the ossifications, the fetus has been stained with AgNO3. Institute of Pathology, Division Photography, Free University Medical Center, Amsterdam. 

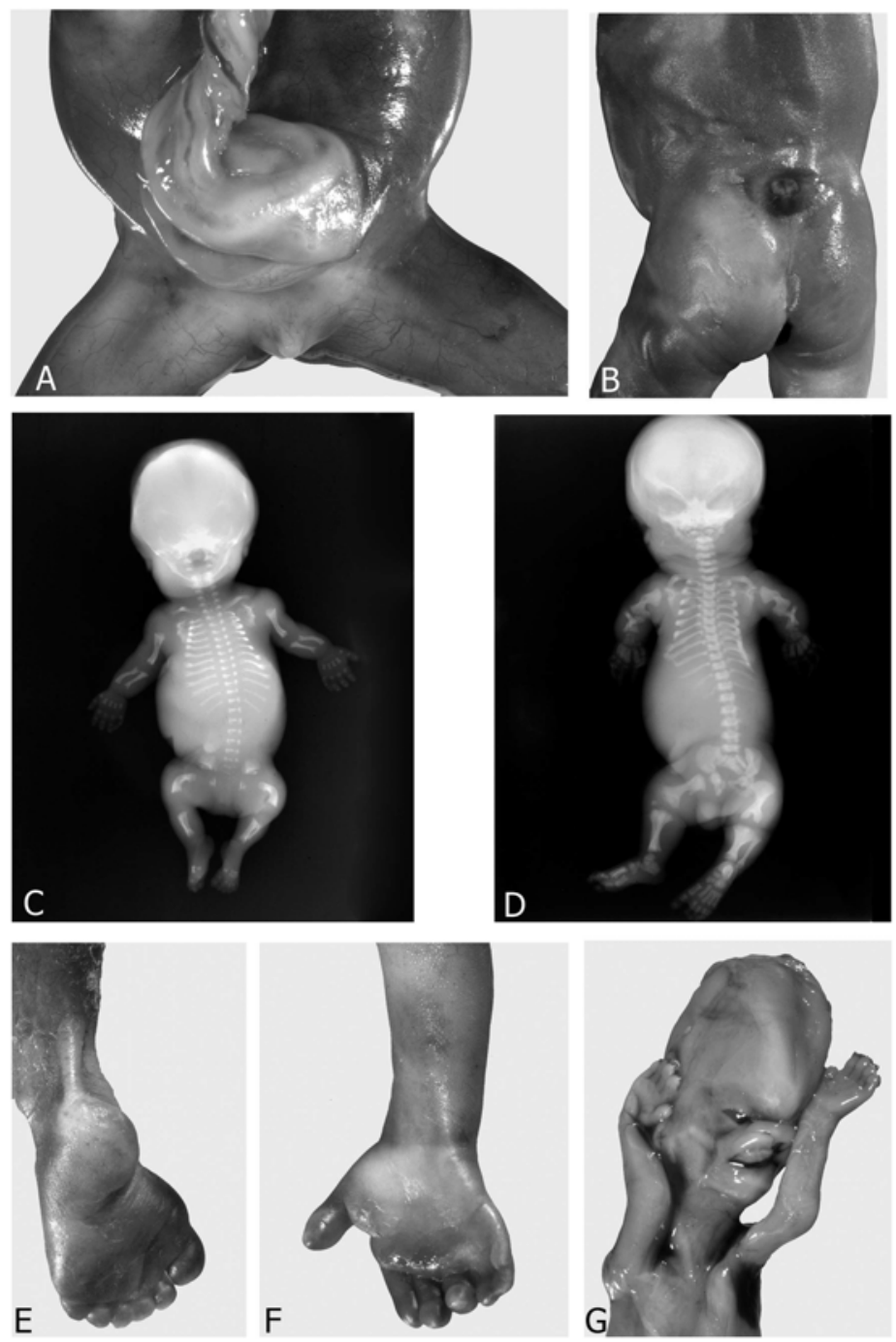

Figure 2. Photographs showing A) Omphalocele (an abdominal wall defect in which the abdominal contents protrude into the base of the umbilical cord) in a male fetus of 20 weeks gestation; B) Spina bifida (a failure of the closure of the neural tube in the lower back region) in a female fetus of 22 weeks of gestation; C) A skeletal dysplasia, thanatophoric dysplasia, with typically curved femurs in the shape of "French telephone receivers", in a female fetus of 22 weeks of gestation; D) Another skeletal dysplasia, Blomstrand dysplasia, characterized by an advanced skeletal maturation, in a male fetus of 32 weeks of gestation; E) and F) Post-axial polydactyly (extra digit posterior to the fifth digit) of foot and hand in a female fetus of 22 weeks of gestation (as part of shortrib-polydactyly syndrome); G) Median cleft lip in a male fetus of 15 weeks of gestation. Institute of Pathology, Division Photography, Free University Medical Center, Amsterdam. 


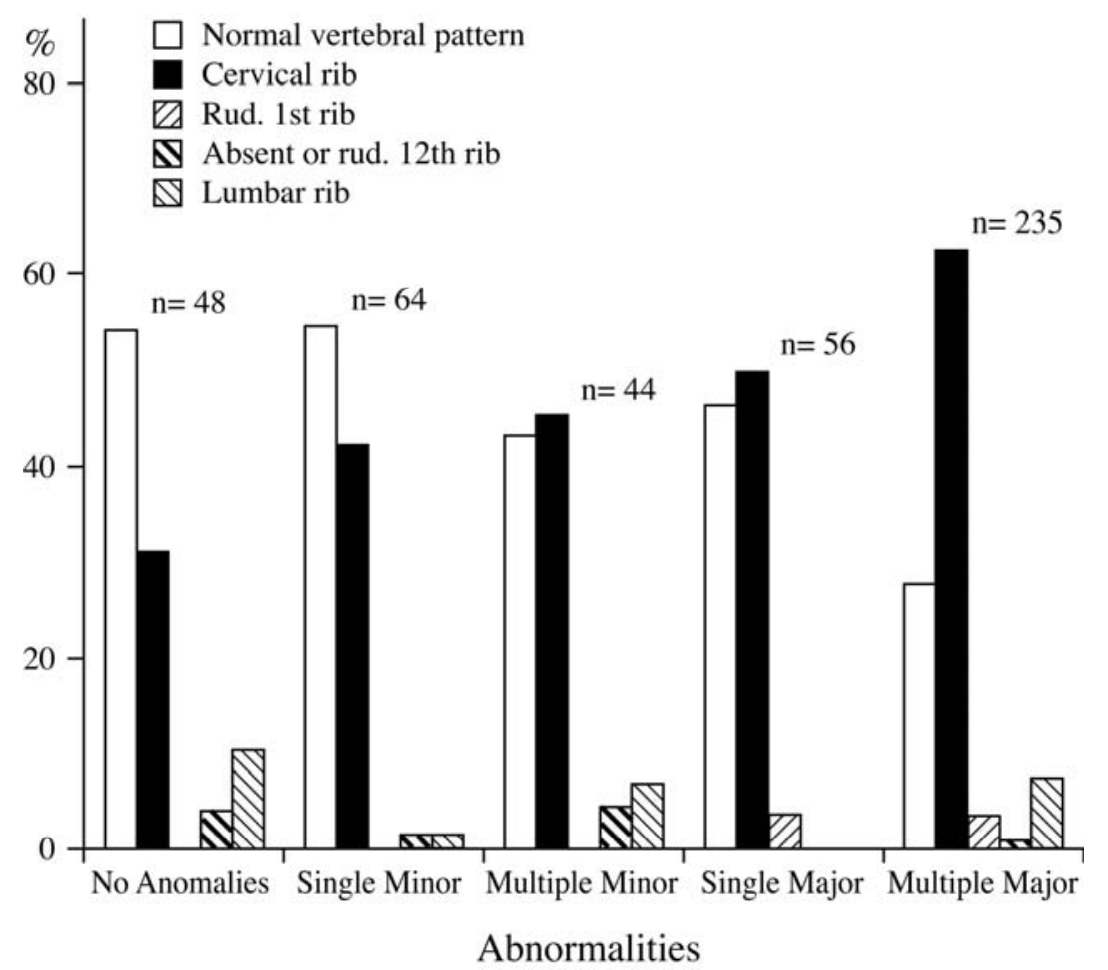

Figure 3. Graph showing the prevalence of cervical ribs, rudimentary first ribs, rudimentary or absent twelfth ribs and lumbar ribs in foetal and infant deaths with resp. no, single minor, single major, multiple minor and multiple major abnormalities. The incidence of cervical ribs increases with the number and severity of the abnormalities. Four cases had two vertebral variations, these were scored in both categories: two cases with a cervical and a lumbar rib, one in the single minor and one in the multiple major group; two cases with cervical ribs and absent $12^{\text {th }}$ ribs (11 ribs including the cervical rib), both in the multiple major abnormalities group. 